Journal of Social Sciences 8 (3): 397-406, 2012

ISSN 1549-3652

(C) 2012 Science Publications

\title{
Cultural Capital and Performance in Medical Education
}

\author{
Karin Darin \\ Center for Research on Public Action and Politics, \\ Faculty of Law, Political and Social Sciences, \\ University of Picardie Jules Verne, \\ Epistemology and Social Sciences (CURAPP) \\ Chemin du thil, 80025 Amiens cedex 1, France
}

\begin{abstract}
Prior research has found that students from higher social classes generally perform at higher levels in education than other students. A common explanation is that these students hold higher volumes of inherited and acquired cultural capital. However, research on the performance of students in specific fields of education is scarce and thus we know little about the variations between fields of education. Since faculties differ in their teaching and evaluation methods, we could expect the performance of groups holding higher and lower volumes of cultural capital to differ between them. The purpose of this study is to create an understanding of the performance of students within the medical field of education in France. The study is based on a longitudinal dataset (1999-2008) and Specific Multiple Correspondence Analysis is used as statistical method. Main finding is that the inherited and acquired cultural capital is important for level of performance during the students' initial years of medical education, while the acquired cultural capital alone is important during the later years. The results suggest that the lack of inherited cultural capital in some cases and to a certain extent, can be compensated for by acquired cultural capital.
\end{abstract}

Key words: Higher education, medical students, cultural capital, social class, educational system, acquired cultural, students perform, different groups, statistical method

\section{INTRODUCTION}

A rather large body of research has looked at the performance of students from different social classes and concluded that students from higher classes generally perform at higher levels in education than students from lower ones (Graaf, 1986; Muller and Karle, 1993). However, research on the performance of students in specific fields of education is scarce. Since faculties differ in their teaching and evaluation methods, we could expect the performance of students to differ between them (cf. Smith and Naylor, 2001; Hansen and Mastekaasa, 2006).

The purpose of this study is to create an understanding of the performance of students within the medical field of education in France. This field of education is interesting to study because it recruits students from the higher social classes in France to a greater extent than many other fields RERS, 2009 and thus provides a social and pedagogical context with which lower classes are less familiar. In this study, medical students enrolled at the University of Picardie Jules Verne (UPJV) in Amiens, France, are studied. Amiens is located in the Picardie region, a previously industrialized area that includes a large working class population. In 2007, for example, $23.1 \%$ of the inhabitants in Picardie were manual workers, compared to $17.6 \%$ of the total population in France (www.insee.fr). Due to the higher working class population in the region, the UPJV is attracting many students from lower social classes (cf. RERS, 2009). For example, in 2008, $14.0 \%$ of students enrolled at UPJV had a working class background, compared to $10.2 \%$ of students enrolled at universities in France in general RERS, 2009.

This study looks at the performance among students in medical education at two different points of time: During the initial years of medical studies and during the later years when the student either enrolls in specialized or general medical training. Many students that enroll in medical studies do not continue studying during the second year of medical education. Between the years 1999 and 2001, a total of 815 students enrolled in the first year of medical studies at UPJV. However, only $36.1 \%$ of them (294 individuals) continued studying during the second year of education. After the sixth year of medical training, students either enroll in generalist or specialized medical training. Among students enrolled between 1999 and 2001 that pursued specialized or generalist medical education after the sixth year, most students $(64.4 \%)$ enrolled to 


\section{J. Social Sci., 8 (3): 397-406, 2012}

obtain a generalist medical doctor degree and the remaining students enrolled in the more competitive field of specialized training. In the following, we will examine what characterizes the students that continued studying during the second year of medical education compared to those who left after the first year, as well as what characterizes the students who enrolled in specialized and generalist medical training after the sixth year of study.

Theoretical framework: Several studies on social class and performance in education have concluded that children from higher classes succeed better in education than students from lower ones (Burnhill et al., 1990; Davies and Guppy, 1997; Bourdieu and Passeron, 1968; Furusten, 2002; Ishida et al., 1995; Mingat, 1981). It has been found that students from higher social classes are overrepresented in higher education, enroll in more theoretical oriented fields of education, pursue longer degrees in higher education and generally receive higher grades (Bourdieu and Passeron, 1968; Muller and Karle, 1993; Furusten, 2002; Smith and Naylor, 2001; Davies and Guppy, 1997; Werfhorst and Luijkx, 2010). In contrast, students from lower social classes less commonly enroll in higher education and when they do, they more commonly enroll in vocational fields of education. They also tend to pursue shorter degrees in higher education and they generally receive lower grades.

Many studies on social class and performance in higher education address the relation between cultural capital and performance. Most of these look at the impact of inherited cultural capital, but some also analyze the students' own acquired cultural capital. In line with Pierre Bourdieu's argument (see below), these studies generally conclude that the unequal distribution of cultural capital causes some students to perform at a higher level than others in education (Hansen and Mastrekaasa, 2006; DiMaggio, 1982; Aschaffenburg and Maas, 1997; Sullivan, 2001; Graaf, 1986; Nakhaie, 1999). Furthermore, it has been found that while inherited cultural capital is important for performance in education, acquired cultural capital can to some extent compensate for the lack of it. The difference in performance between students holding higher and lower volumes of inherited cultural capital has been found to decrease with years in education during which the student acquires cultural capital (Aschaffenburg and Maas, 1997).

This study is theoretically based on the work by Pierre Bourdieu. Bourdieu argued that groups of individuals hold social positions relative to one another depending on their capital volume, as well as their different forms of capital and thus that social reality is multidimensional (Bourdieu, 1984). Economic and cultural capital is the two forms of capital that will be discussed in this study. Capital is either inherited over generations or acquired during the course of one's life. Economic capital refers to various kinds of financial assets and material resources, such as wealth and property rights. It also refers to knowledge about the rules of the economy, such as how to maximize economic returns (Lebaron, 2002). Cultural capital in embodied form refers to level of cultivation, i.e., knowledge about and a taste for, legitimate music and literature in society, possession of cultivated speech and overall intellectual curiosity (Granovetter and Swedberg, 2001). The accumulation of cultural capital depends heavily on its initial presence at home during childhood (i.e., inherited cultural capital). If the parents hold a higher volume of cultural capital, the child embodies it from an early age and is generally guided towards its future acquisition (ibid). Furthermore, the cultural capital is to a great extent produced and reproduced by the educational system. The Academic culture, its way of evaluating students, of presenting arguments, language used and subjects taught, is in favor of students endowed with higher volumes of cultural capital (ibid). These students are disposed to feel more at ease within the academic context and in contrast, students with lower volumes of cultural capital are more disadvantaged.

\section{MATERIALS AND METHODS}

Medical education in France: Before moving on to a discussion about the population and statistical method, I will briefly discuss the organization of medical studies in France. Medical education in France includes three cycles. The first two years constitute the first cycle and the following four years the second cycle. The first two cycles of medical studies are attended by all students in medicine, regardless of their future specialization. After the first year in the first cycle, all students have to sit a competitive examination which provides successful students with access to the second and following years of medical studies. If unsuccessful at the examination, the student is allowed to retake the first year and the following examination only once. After the sixth year, students proceed either towards obtaining a generalist medical doctor degree or specializing in some specific field of medicine. The generalist degree requires an additional three years of education, while the 'specialist' degree requires an additional four to six years depending on the specialization. The years following the second cycle compose the third cycle of medical studies, during which the students do an internship (French: Internat). After the second cycle, all students in medicine have to sit a competitive examination (L'Examen National Classant). Depending on their scores on this 


\section{J. Social Sci., 8 (3): 397-406, 2012}

examination, they choose a field of specialization and a city for their internship. After completing an education in medicine, students receive the degree DE (degree of medical doctor) (French: diplôme d'état de docteur en médicine), as well as the degree DES (degree of specialist studies) (French: diplôme d'études spécialisées).

Population: This study is carried out on a population of students enrolled for the first time in the first year of the first cycle in medical education at the UPJV during the years 1999-2001. In total during these years, 878 students entered the first year of medical studies. In the statistical analysis, students lacking information in several variables have been excluded. In the end, 815 students were analyzed further.

The data is acquired from registration files with information provided by students at enrollment each year and it covers ten years of information: 1999-2008.

Specific MCA: Specific Multiple Correspondence Analysis (MCA) is used as statistical method. This method captures relations between larger numbers of variables simultaneously and presents relations between these variables in different dimensions (along different axes). Hence, it is a method well suited to capturing the multidimensionality of social reality and relations between larger sets of variables. The results produced by the Specific MCA are based on frequencies and chi square distances (Roux and Rouanet, 2004). The method takes as a starting point a table containing individuals as rows and variable values as columns and presents the results in a Euclidean space. The space is presented with different axes, each accounting for a certain percentage of the variance that can be found in the material. In the interpretation of the results, focus is on the relations between individuals having different profiles. Individuals that have similar profiles in one dimension are placed closer together along that axis, while individuals that have more distinct profiles are placed further apart.

Specific MCA produces two Euclidean spaces: the space of modalities and the space of individuals. The space of individuals is presented with a number of points in the geometrical space produced by the Specific MCA (ibid). Modalities used to construct the space are called active modalities and individuals included in the construction of the space are called active individuals. Supplementary individuals, variables and modalities are introduced in the analysis so as to not affect the structure created by the active modalities (ibid). In this study, individuals described as excluded from the analysis in the prior section, are placed as supplementary. Furthermore, variables showing the performance of students are included in the analysis as supplementary elements. The distances between modalities are presented in standard deviations (ibid). Standard deviations at $\geq 0.5$ are considered to be more important while standard deviations lower than that are considered to be less important (ibid).

\section{RESULTS AND DISCUSSION}

Active variables and modalities: Indicators of cultural and economic capital are included as active elements in the following analysis, as well as a variable showing father's occupation, which is used as an indicator of social class. Furthermore, the occupational status of the father is used as an indicator of his level of education, i.e., fathers in professions are more likely to hold university degrees than fathers in manual labor and thus this variable also indicates volume of inherited cultural capital. Table 1 presents the seven active variables and 21 active modalities in the study. The first variable shows fathers' occupations, the second variable reveals if the student is a scholarship holder or not and the third variable shows the students' types of lodging. Whether or not the student holds a scholarship is used as indicator of inherited economic capital, since students having this kind of financial support in France generally derive from economically poorer family backgrounds. Type of lodging is also used as an indicator of inherited economic capital, since having an own residence presumably requires more financial resources than other kinds of lodging. Since the student generally is young, it is likely that parents support students living by their own.

Following these variables, are variables showing capital related to secondary education.

A majority of students, 96\%, have a degree in science from secondary school (a so called baccalauréat scientifique) and thus it is meaningless to introduce a variable showing kind of secondary education in the statistical analysis. However, the students have obtained their baccalauréat (bac) from different kinds of secondary schools and thus two variables revealing kind of secondary school have been introduced in the analysis. The first variable shows whether the school was private or public and the second one whether it was a professional or general/technical kind of school (The professional school offers mainly vocational diplomas, while the general/technical school offers mainly theoretical ones). The third variable includes information about the students' grades from secondary school and is divided into three modalities: passable, assez bien, bien/très bien (passable being the lowest grade and bien/très bien the highest ones merged). 
J. Social Sci., 8 (3): 397-406, 2012

Table 1: Active variables and modalities: frequencies, percentages, coordinates and contributions along axes

\begin{tabular}{|c|c|c|c|c|c|c|}
\hline \multirow[b]{2}{*}{ Father's occupation } & \multicolumn{3}{|c|}{ Axis 1} & \multicolumn{3}{|c|}{ Axis 2} \\
\hline & $\mathrm{N}$ & $\%$ & $\mathrm{y}_{1}$ & Ctr & $\mathrm{y}_{2}$ & $\mathrm{Ctr}$ \\
\hline Professionals & 315 & 38.7 & -0.64 & 8.9 & +0.05 & 0.1 \\
\hline Intermediate non-manual employees & 273 & 33.5 & -0.19 & 0.7 & +0.13 & 0.4 \\
\hline Assistant non-manual employees & 74 & 9.2 & +0.52 & 1.4 & +0.06 & 0.0 \\
\hline Workers & 149 & 28.3 & +1.44 & 21.4 & -0.37 & 1.8 \\
\hline Missing information & 4 & 0.5 & & & & \\
\hline Total & 815 & 100.0 & & 32.4 & & 2.3 \\
\hline \multicolumn{7}{|l|}{ Scholarship holder year of enrolling } \\
\hline Scholarship & 272 & 33.4 & +1.08 & 22.2 & -0.05 & 0.1 \\
\hline No scholarship & 543 & 66.6 & -0.54 & 11.1 & +0.03 & 0.0 \\
\hline Total & 815 & 100.0 & & 33.4 & & 0.1 \\
\hline \multicolumn{7}{|l|}{ Type of lodging first year } \\
\hline Own residence & 254 & 31.2 & -0.04 & 0.0 & +0.21 & 1.0 \\
\hline Other type of lodging & 561 & 68.8 & +0.02 & 0.0 & -0.10 & 0.5 \\
\hline Total & 815 & 100.0 & & 0.0 & & 1.5 \\
\hline \multicolumn{7}{|l|}{ Public/Private secondary school } \\
\hline Private school & 216 & 26.5 & -0.79 & 9.5 & -1.03 & 20.5 \\
\hline Public school & 599 & 73.5 & +0.29 & 3.4 & +0.37 & 7.4 \\
\hline Total & 815 & 100.0 & & 12.9 & & 27.9 \\
\hline \multicolumn{7}{|l|}{ Professional-General/Technical } \\
\hline \multicolumn{7}{|l|}{ Secondary School } \\
\hline Professional school & 94 & 11.5 & -0.46 & 1.4 & -2.14 & 37.9 \\
\hline General/Technical & 715 & 87.7 & +0.06 & 0.2 & +0.28 & 4.9 \\
\hline Other & 6 & 0.7 & & & & \\
\hline Total & 815 & 100.0 & & 1.6 & & 42.8 \\
\hline \multicolumn{7}{|l|}{ Grade on Baccalauréat } \\
\hline Passable & 492 & 60.4 & +0.33 & 3.7 & -0.14 & 0.9 \\
\hline Assez bien & 201 & 24.7 & -0.33 & 1.5 & -0.14 & 0.4 \\
\hline Bien/Très bien & 122 & 15.0 & -0.79 & 5.2 & +0.80 & 6.9 \\
\hline Total & 815 & 100.0 & & 10.4 & & 8.1 \\
\hline \multicolumn{7}{|l|}{ Age when receiving the Baccalauréat/Sex } \\
\hline$\leq 17$ years (both male/female) & 91 & 11.2 & -0.75 & 3.5 & +0.69 & 3.8 \\
\hline Female 18 years & 368 & 45.2 & -0.01 & 0.0 & +0.27 & 2.4 \\
\hline Male 18 years & 202 & 24.8 & -0.14 & 0.3 & -0.12 & 0.3 \\
\hline Female $\geq 19$ years & 82 & 10.1 & +0.93 & 5.0 & -0.98 & 7.1 \\
\hline Male $\geq 19$ years & 72 & 8.8 & +0.31 & 0.5 & -0.77 & 3.8 \\
\hline Total & 815 & 100.0 & & 9.3 & & 17.3 \\
\hline
\end{tabular}

Table 2: Eigenvalues, modified rates and cumulated modified rates

\begin{tabular}{lcc}
\hline & Axis 1 & Axis 2 \\
\hline Eigenvalues & 0.252 & 0.198 \\
Modified rates & 62.400 & 20.800 \\
\hline
\end{tabular}

Table 3: Supplementary variables used to examine performance

\begin{tabular}{|c|c|c|c|c|c|}
\hline Variables & Modalities & $\mathrm{n}$ & $\%$ & $\mathrm{y}_{1}$ & $\mathrm{y}_{2}$ \\
\hline \multirow[t]{4}{*}{$\begin{array}{l}\text { Entry into } 2^{\text {nd }} \\
\text { year of medical }\end{array}$} & $\begin{array}{l}\text { Retook } 1^{\text {st }} \text { year/ } \\
\text { entered } 2^{\text {nd }} \text { year }\end{array}$ & 193 & 23.7 & -0.32 & +0.14 \\
\hline & $\begin{array}{l}\text { Retook } 1^{\text {st }} \text { year/did } \\
\text { not enter } 2^{\text {nd }} \text { year } \\
\text { Did not retake } 1^{\text {st }} \text { year }\end{array}$ & 322 & 39.5 & +0.19 & -0.18 \\
\hline & $\begin{array}{l}\text { /entered } 2^{\text {nd }} \text { year } \\
\text { Did not retake } 1^{\text {st }} \text { year }\end{array}$ & 101 & 12.4 & -0.67 & +0.54 \\
\hline & $/$ did not enter $2^{\text {nd }}$ year & 199 & 24.4 & +0.34 & -0.10 \\
\hline \multirow{3}{*}{$\begin{array}{l}\text { Type of } \\
\text { specialization } \\
\text { for the DES }\end{array}$} & Generalist & 103 & 12.6 & -0.33 & +0.10 \\
\hline & Specialist & 57 & 7.0 & -0.48 & +0.57 \\
\hline & No DES & 655 & 80.4 & +0.09 & -0.07 \\
\hline
\end{tabular}

Furthermore, the variable showing age when obtaining the baccalauréat is divided into five modalities and merged with sex (This combination of sex and graduation age has been introduced in the analysis because it has a stronger contribution than graduation age and sex per se). Students generally obtain their baccalauréat at the age of 18. Students obtaining their diploma at age 17 or younger have generally skipped classes and students obtaining their diploma at age 19 or older have most likely retaken classes. All variables related to secondary education are indicators of acquired cultural capital. In addition, besides being an indicator of acquired cultural capital, the variable showing whether the student attended private or public secondary school indicates volume of inherited economic capital, since enrollment in private schools require financial resources.

The variables in Table 1 generate 20 axes, two of which will be discussed further in the following analysis. The first axis contributes with $62.4 \%$ to the variance and the second one with $20.8 \%$ (Table 2). Taken together, the first two axes explain $83.2 \%$ of the total variance. The contribution of each variable and modality to the two first axes, as well as the coordinates of the modalities, are presented in Table 1. The average 


\section{J. Social Sci., 8 (3): 397-406, 2012}

contribution of variables is 14.3 and of modalities; 5.0. Variables contributing close to the average $(\geq 9.3)$ and modalities doing so $(\geq 3.4)$, have been retained in the following interpretation of the axes.

Students in medicine: Figure 1 shows the modalities contributing above average to the first and second axes. The oppositions between modalities that we can see in the figure show what characterizes different groups of students in the medical field of education. The first axis will be discussed initially, followed by the second. Taken together, 10 modalities contribute above average to the first axis. To the right of the space, we find students whose parents are workers, went to public secondary school and received the grade 'passable' on their diploma. The modality 'female/bac19+' shows that these students were older when obtaining their baccalauréat and especially so the female fraction of the group. Furthermore, many students in this group hold scholarships. On the opposite side, to the left of the space, we find students with parents who are professionals and who have attended private secondary schools. Furthermore, these students were younger (17 years old or less) when obtaining their baccalauréat. Hence, it is a group of students among whom we find individuals that have skipped classes in primary/secondary school. They have also received the highest grades on their baccalauréat, i.e., bien or très bien. In contrast to the oppositely placed students, these students generally do not hold any scholarship.

Taken together, the first axis shows an opposition between students holding a lower volume of inherited cultural capital to the right and students holding a higher volume to the left. The inherited cultural capital has been reproduced among the children. As we can see, students with a higher volume of inherited cultural capital have acquired a higher volume of cultural capital. In addition, the higher volume of cultural capital is related to a higher volume of inherited economic capital, the students to the left of the space have attended private secondary schools and hold no scholarship, which in this context indicates a higher volume of inherited economic capital.

The second dimension of the space concerns the acquired cultural capital alone. Taken together, eight modalities contribute to the second axis. In the upper part of the space we find students who attended public secondary schools, as well as general/technical schools offering mainly theoretical diplomas. They received the highest grades on their baccalaureate and they were younger than average when obtaining it. The opposite group of students (at the bottom of the space) went to private secondary schools and to professional schools rather than general/technical ones. These students were also older when receiving their baccalaureate. Taken together, the second axis places a group of students with a higher volume of acquired cultural capital (upper part of the space) opposite a group of students with a lower volume (bottom part of the space). For simplicity, in the following discussion I will refer to cultural capital as being specific for the first axis and educational capital as being specific for the second one, since the first axis concerns both the inherited and acquired cultural capital, while the second axis concerns the acquired cultural capital alone (which has been acquired through education).

Performance among medical students: Figure 2 shows the cloud of individuals in the plane of axes 1 and 2. Each dot represents a student in medicine. We can see that the cloud is rather evenly distributed in the space. The fact that the students are not more concentrated towards a certain pole of the space means that students holding the different profiles discussed so far are equally represented in medical education.

In the following, we will take a look at the performance of students in medicine. The variables used to examine the students' performance and the coordinates of modalities, are presented in Table 3. These variables are introduced as supplementary elements in the analysis. By doing so, we gain an understanding of performance among the different groups of students discussed so far. Each modality is placed in the mean point of its subcloud, i.e., in the mean point of all students sharing the property revealed by the modality.

Among the 815 students entering medical studies at the UPJV between the years 1999 and 2001, 36.1\% pass the examination following the first year and thus enter the second year of the first cycle. Hence, the majority of students enrolling in the field of medicine do not continue to the second year of education. Furthermore, about $63.2 \%$ of all students entering the field of medicine retake the first year of education. Hence, retaking the first year is rather a rule than an exception, which also demonstrates how difficult it actually is to enter this field of education. Among all students, $23.7 \%$ retake the first year and enter the second one, while 39.5 retake the first year and do not enter the second year. In Fig. 3, we can see the modalities showing whether or not the students retook the first year and entered the second one. We can see that the modalities showing students who do not enter the second year of medical studies are placed somewhat towards the lower right part of the space and thus these students tend to have a lower volume of cultural capital, as well as acquired educational capital. 


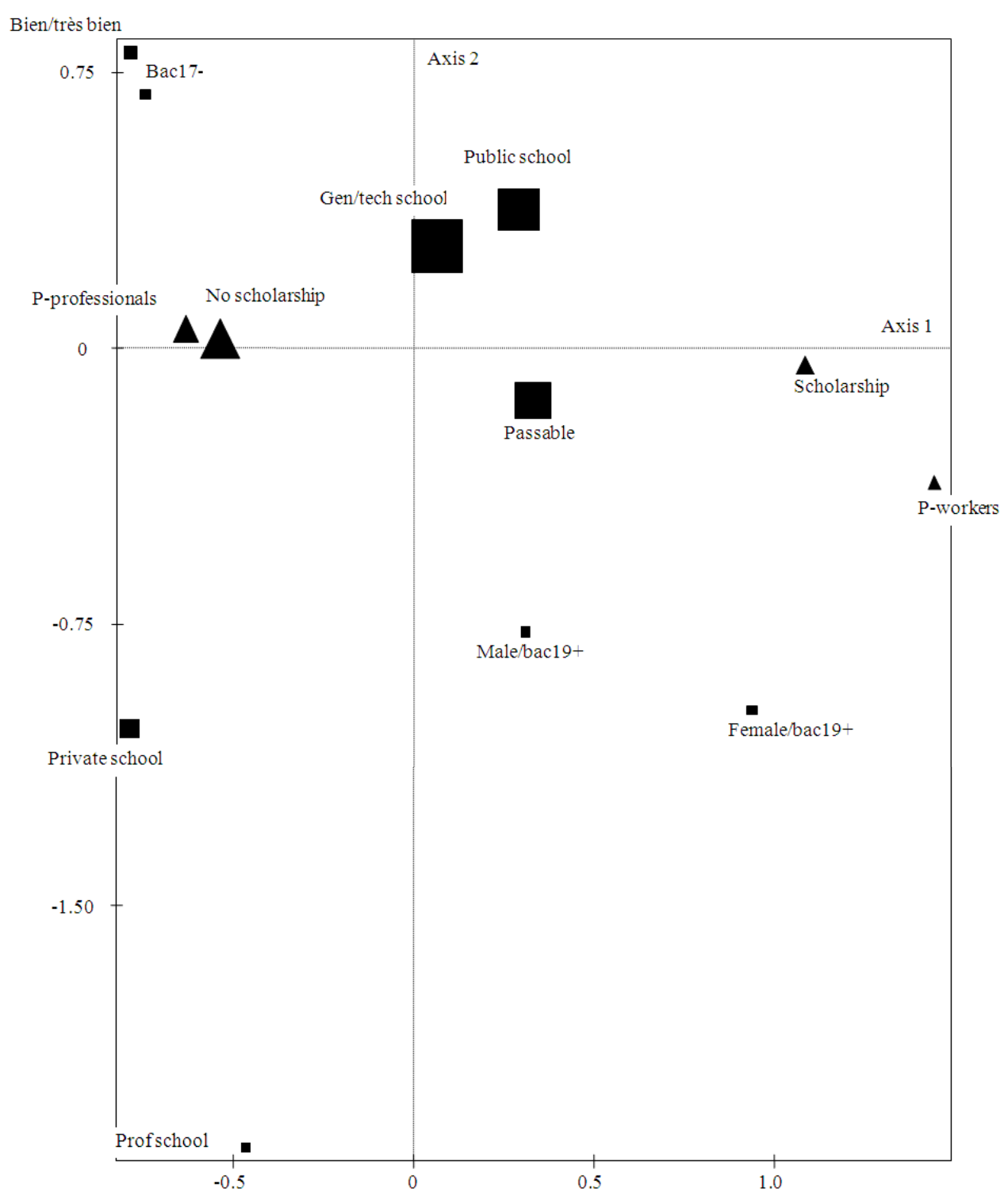

Fig. 1: Axis 1 and 2. 10 modalities contribute over average to axis 1 and 8 modalities to axis 2. $\mathbf{\Delta}$ Inherited capital, Educational capital

In contrast, the modalities showing students who do enter the second year of medical training are placed towards the upper left part of the space. Hence, these students have a higher volume of cultural and educational capital. For example, the standard deviation between students who enter the second year of medical training and students who do not, both without retaking the first year, is 1.1 along the first axis and 0.6 along the second one. Hence, students entering the second year of medical education have an entirely different capital composition from students not entering the second year and both the cultural and educational capital distinguishes them for one another.
Furthermore, while the modalities for students not entering the second year of medical training are placed rather close to one another regardless of whether the student retook the first year or not, the modalities for students entering the second year, with or without retaking the first one, are placed far apart. Students entering the second year of education without retaking the first one are placed closer to the upper left corner of the space than students entering the second year after retaking the first one. The standard deviation between students retaking the first year and entering the second and students not retaking the first year and entering the second, is 0.35 along the first axis. 


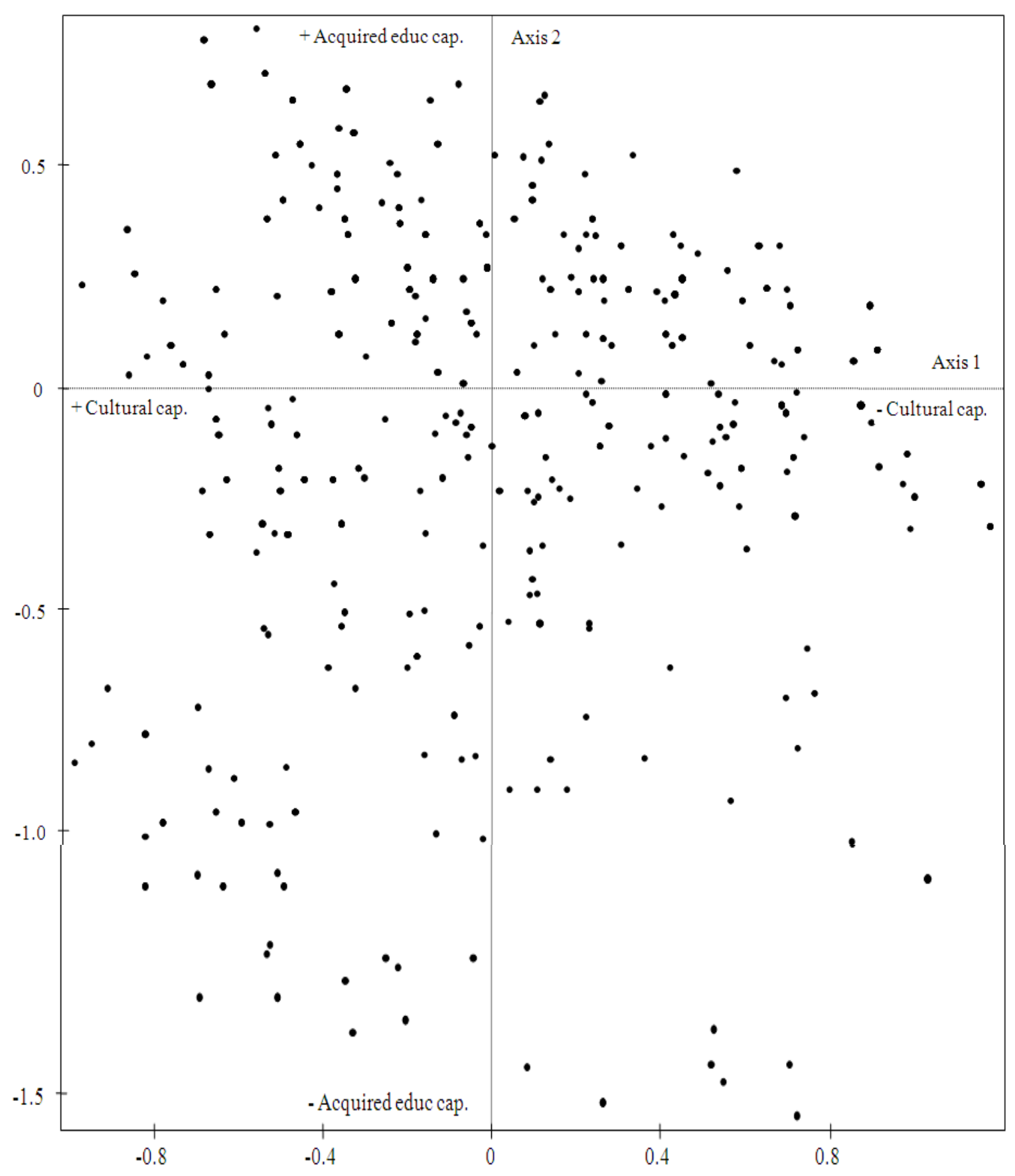

Fig. 2: Axes 1 and 2. Cloud of individuals

Along the second axis, the standard deviation is 0.38 . This result means that although students who enter the second year are similar in the sense that they have higher volumes of cultural and educational capital than the average student entering medical training, there is a difference in capital composition among them. Students entering the second year directly after the first one have a higher volume of cultural and educational capital than students retaking the initial year.

Figure 4 shows what kind of medical training the students enroll in after the sixth year. The standard 
deviation between the modalities showing generalist and specialist medical training along the first axis is 0.15 and along the second one it is 0.47 . Hence, it is primarily the second axis that separates these two groups of students, which means that it is rather the educational capital than the cultural capital that distinguishes them from one another. However, we can see that both modalities showing specialization are placed closer to the left part of the space, which means that many of the students who have lower volumes of cultural capital have left medical education already after the first year.

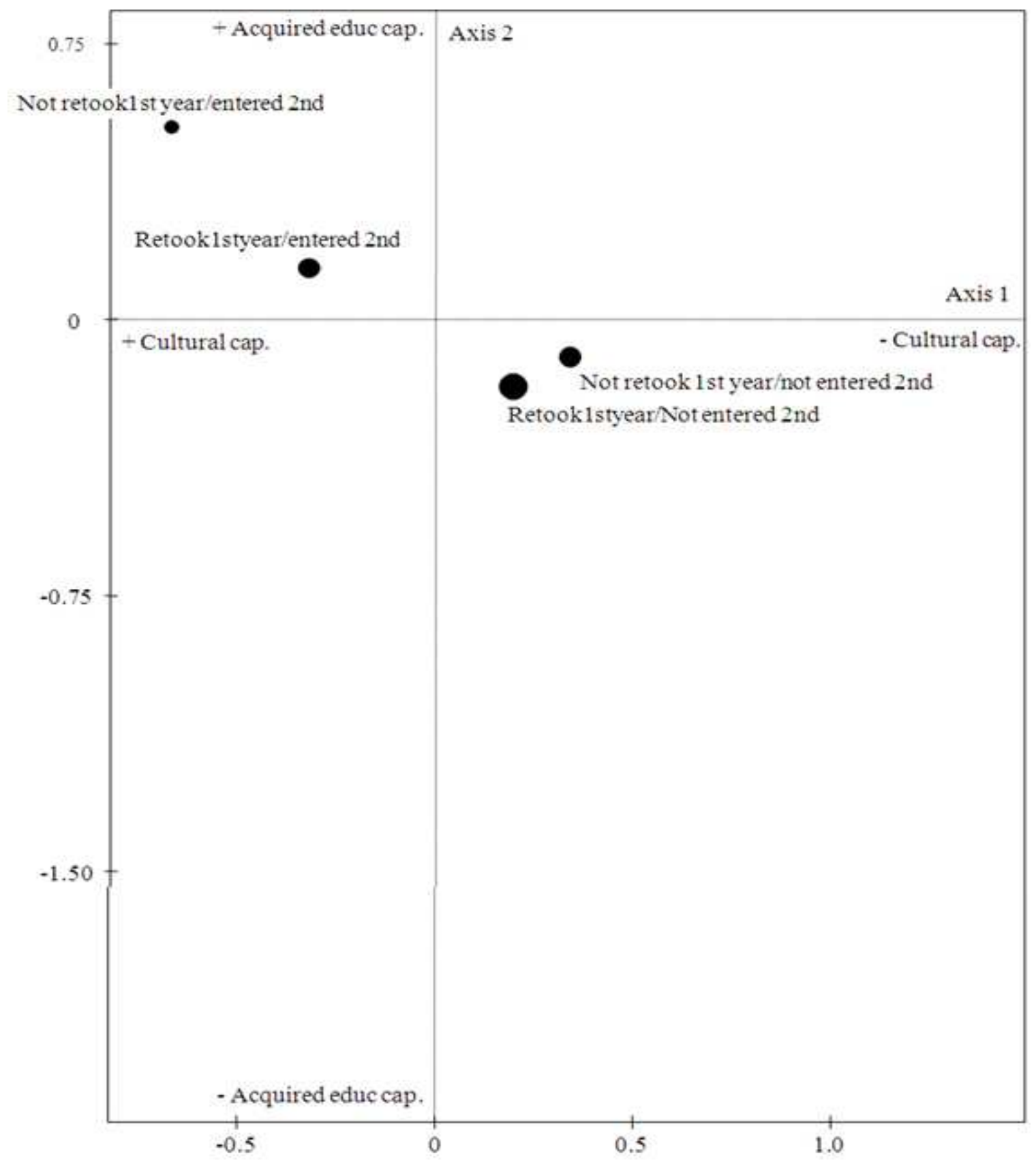

Fig. 3: Axis 1 and 2. Modalities showing whether or not the students retook the first year and entered the second Characteristics of the different groups of students are written in the corners of the figure 


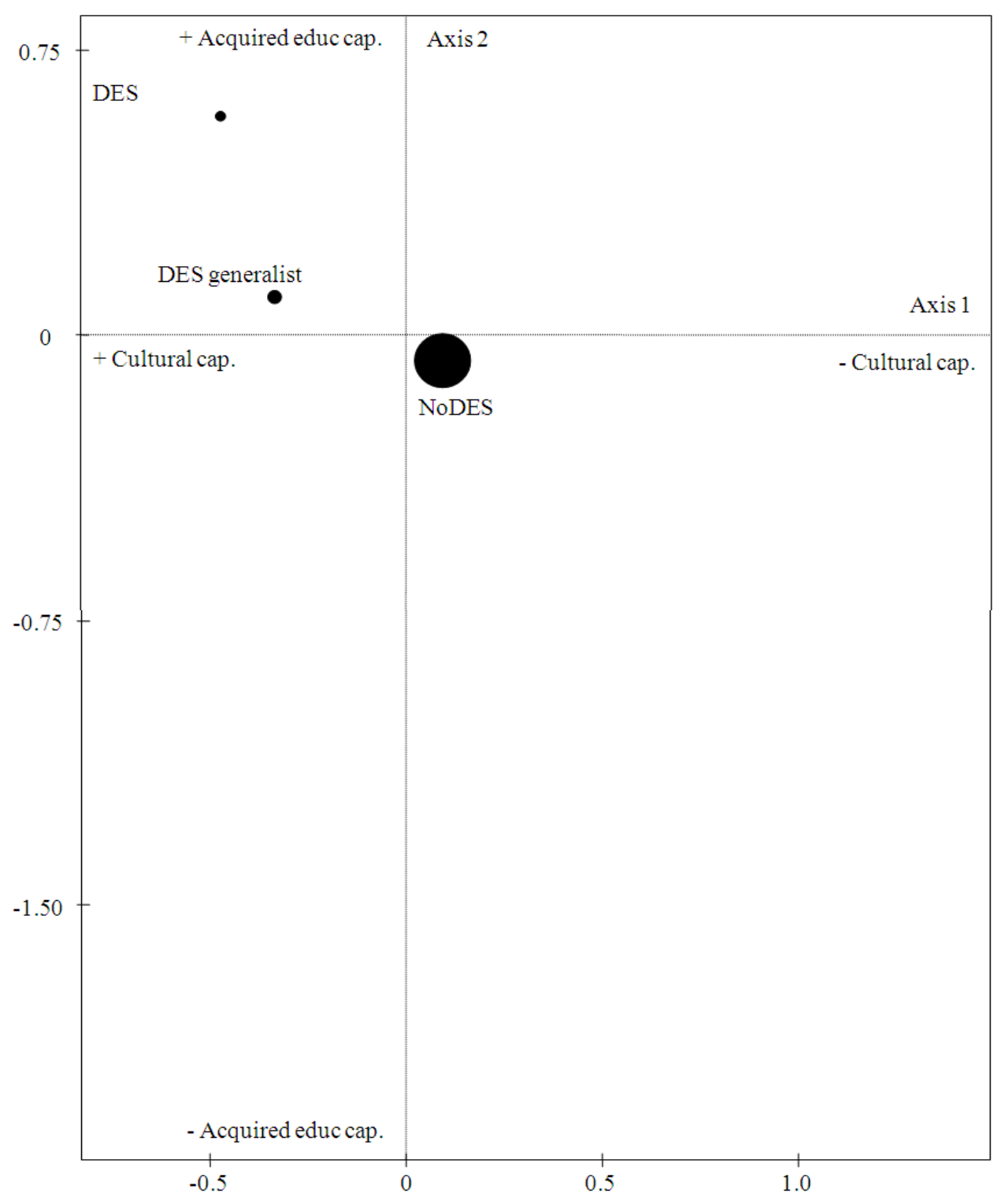

Fig. 4:Axis 1 and 2. Modalities showing kind of specialization in medicine (NoDes shows student leaving medical training after the first year). Characteristics of the different groups of students are written in the corners of the figure

\section{CONCLUSION}

This article has presented a study of medical students enrolled at the University of Picardie Jules Verne in France. The purpose has been to create an understanding of the performance of students within the medical field of education. We have seen that there are two main distinctions between the students. The first one is between students holding higher and lower volumes of cultural capital (inherited and acquired) and the second is between students holding higher and lower volumes of educational capital (i.e., acquired cultural capital). The results have shown that students with higher volumes of cultural capital pass the competitive examination given after the first year and gain access to the second and subsequent years of medical education, to a greater extent than other students. Students who hold lower volumes of cultural capital do not enter the second year to the same extent. The difference between students entering the second 
year of medical training and students not doing so has shown to be important. Furthermore, we could see that students with lower volumes of cultural and educational capital either retake the first year to once again fail entering the second year of education, or leave after the first attempt to enter. In contrast, students with higher volumes of cultural and educational capital tend to enter the second year on the first or second attempt. However, students entering the second year of medical training on the first attempt hold higher volumes of cultural and educational capital than those entering the second year on the second attempt. Lastly, students enrolling in the more competitive specialized medical training hold a higher volume of educational capital than students pursuing medical practice as generalists, the inherited cultural capital plays no role here.

Taken together, the results have shown that both the inherited and acquired cultural capital (the latter referred to as educational capital throughout the previous discussion) is important for succeeding in medical education. However, while both the inherited and acquired cultural capital is important for entering the second year of medical education, the acquired cultural capital alone is important for the kind of specialization students pursue later on in their educational careers. We could see that students with higher volumes of inherited cultural capital more commonly entered the second year of medical training, while students with higher volumes of acquired cultural capital regardless of volume of inherited cultural capital more commonly pursued specialized medical training. Hence, the acquired cultural capital can to some extent compensate for the lack of inherited cultural capital. However, for students lacking volume of inherited cultural capital when enrolling in medical education, chances are they will not pass the competitive examination required to enroll in the following years of medical training. Since foremost students with inherited cultural capital enter the second year of medical training, it is foremost these students competing to enroll in specialized training after the sixth year.

\section{REFERENCES}

Aschaffenburg, K. and I. Maas, 1997. Cultural and educational careers: The dynamics of social reproduction. Am. Soc. Rev., 62: 573-587.

Bourdieu, P. and J.C. Passeron, 1968. Les Héritiers, les Étudiants et la Culture. 1st Edn., Éditions de Minuit, Paris, pp: 191.

Bourdieu, P., 1984. Distinction: A Social Critique of the Judgement of Taste. 1st Edn., Harvard University Press, Cambridge, ISBN-10: 0674212770, pp: 613.
Burnhill, P., C. Garner and A. McPherson, 1990. Parental education, social class and entry to higher education 1976-86. J. Royal Stat. Soc., 153: 233-248.

Davies, S. and N. Guppy, 1997. Fields of study, college selectivity, and student inequalities in higher education. Soc. Forces, 75: 1417-1438. DOI: 10.1093/sf/75.4.1417

DiMaggio, P., 1982. Cultural capital and school success: The impact of status culture participation on the grades of U.S. high school students. Am. Soc. Rev., 47: 189-201.

Furusten, T., 2002. Perspektiv på högskolan i ett förändrat Sverige. Högskoleverket, Stockholm, ISBN-10: 9188874915, pp: 154.

Graaf, P.M.D., 1986. The impact of financial and cultural resources on educational attainment in the netherlands. Soc. Educ., 59: 237-246.

Granovetter, M.S. and R. Swedberg, 2001. The Sociology of Economic Life. 2nd Edn., Westview Press, Boulder, Colorado, ISBN-10: 0813397642, pp: 536.

Hansen, M.N. and A. Mastekaasa, 2006. Social origins and academic performance at university. Eur. Soc. Rev., 22: 277-291. DOI: 10.1093/esr/jci057

Ishida, H., W. Muller and J.M. Ridge, 1995. Class origin, class destination, and education: A crossnational study of ten industrial nations. Am. J. Soc., 101: $145-193$. DOI: $10.1086 / 230701$

Lebaron, F., 2002. Dispositions, Social Structures and Economic Practices: Towards a new Economic Sociology. Intersubjectivity Econ. DOI: 10.4324/9780203116661.ch14

Mingat, A., 1981. Aptitudes et classes sociales. Accès et succès dans l'enseignement supérieur. Population (French Edition), 36: 337-359.

Muller, W. and W. Karle, 1993. Social selection in educational systems in europe. Eur. Soc. Rev., 9: 1-23.

Nakhaie, M.R., 1999. Social origins and educational attainment in Canada: 1985 and 1994. Rev. Radical Political Econ., 32: 577-609. DOI: 10.1016/S04866134(00)90002-0

Roux, B.L. and H. Rouanet, 2004. Geometric Data Analysis: From Correspondence Analysis to Structured Data Analysis. 1st Edn., Springer, ISBN-10: 1402022352, pp: 475.

Smith, J. and R. Naylor, 2001. Determinants of degree performance in UK universities: A Statistical Analysis of the 1993 Student Cohort. Oxford Bull. Econ. Stat., 63: 29-60. DOI: 10.1111/14680084.00208

Sullivan, A., 2001. Cultural capital and educational attainment. Sociology, 35: 893-912.

Werfhorst, H.G.V.D. and R. Luijkx, 2010. Educational field of study and social mobility: Disaggregating social origin and Education. Sociology, 44: 695715. DOI: $10.1177 / 0038038510369362$ 